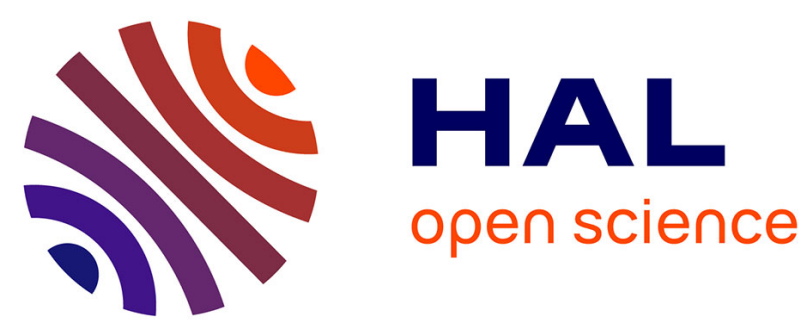

\title{
Differences in effective connectivity between dyslexic children and normal readers during a pseudoword reading task: An fMRI study
}

Véronique Quaglino, B. Bourdin, G. Czternasty, P. Vrignaud, S. Fall, M.E. Meyer, P. Berquin, Bernard Devauchelle, Giovanni de Marco

\section{To cite this version:}

Véronique Quaglino, B. Bourdin, G. Czternasty, P. Vrignaud, S. Fall, et al.. Differences in effective connectivity between dyslexic children and normal readers during a pseudoword reading task: An fMRI study. Neurophysiologie Clinique = Clinical Neurophysiology, 2008, 38 (2), pp.73-82. 10.1016/j.neucli.2007.12.007 . hal-02310864

\section{HAL Id: hal-02310864 \\ https://hal.parisnanterre.fr/hal-02310864}

Submitted on 10 Oct 2019

HAL is a multi-disciplinary open access archive for the deposit and dissemination of scientific research documents, whether they are published or not. The documents may come from teaching and research institutions in France or abroad, or from public or private research centers.
L'archive ouverte pluridisciplinaire HAL, est destinée au dépôt et à la diffusion de documents scientifiques de niveau recherche, publiés ou non, émanant des établissements d'enseignement et de recherche français ou étrangers, des laboratoires publics ou privés. 


\title{
Differences in effective connectivity between dyslexic children and normal readers during a pseudoword reading task: An fMRI study Différences de connectivité effective entre des enfants dyslexiques et des enfants lecteurs normaux pendant une tâche de lecture de pseudomots: une étude par IRMf
}

\author{
V. Quaglino ${ }^{a}$, B. Bourdin ${ }^{a}$, G. Czternasty ${ }^{a}$, P. Vrignaud $^{b}$, S. Fall ${ }^{c}$, \\ M.E. Meyer ${ }^{c}$, P. Berquin ${ }^{d}, B$. Devauchelle ${ }^{e}$, G. de Marco ${ }^{c, *}$ \\ a Efficience cognitive dans les conduites humaines d'apprentissage et de travail, Ecchat, EA 2092, université de \\ Picardie-Jules-Verne, Amiens, France \\ ${ }^{\mathrm{b}}$ Laboratoire universitaire de developpement social et emotionnel, EA1588, université Paris-X, France \\ c Laboratoire de traitement de l'image médicale, UPJV, CHU Nord, place Victor-Pauchet, 80054 Amiens cedex, France \\ d Service de neuropédiatrie, CNRS FRE 2726, CHU Nord, Amiens, France \\ e Service de chirurgie maxillofaciale et stomatologie, CHU d'Amiens, hôpital Nord, \\ place Victor-Pauchet, 80054 Amiens cedex 01, France
}

Received 8 June 2007; accepted 31 December 2007

\section{KEYWORDS}

Structural equation modeling;

Effective

connectivity;

Developmental

dyslexia;
Summary

Purpose. - This fMRI study investigated phonological and lexicosemantic processing in dyslexic and in chronological age- and reading level-matched children in a pseudoword reading task. Materials and methods. - The effective connectivity network was compared between the three groups using a structural model including the supramarginal cortex (BA 40; BA: Brodmann area), fusiform cortex (BA 37) and inferior frontal cortex (BA 44/45) areas of the left hemisphere. Results. - The results revealed differences in connectivity patterns. In dyslexic patients, in contrast with chronological age- and reading level-matched groups, no causal relationship was

\footnotetext{
* Corresponding author.

E-mail address: demarco.giovanni@chu-amiens.fr (G. de Marco).
} 
fMRI;

Phonological

processing

MOTS CLÉS

Modélisation par

équations

structurelles ;

Connectivité

effective ;

Dyslexie

développementale ;

IRMf ;

Processus

phonologiques demonstrated between BA 40 and BA 44/45. However, a significant causal relationship was demonstrated between BA 37 and BA 44/45 both in dyslexic children and in the reading levelmatched group.

Conclusions. - These findings were interpreted as evidence for a phonological deficit in developmental dyslexia.

\section{Résumé}

But. - Explorer par imagerie fonctionnelle d'activation cérébrale chez l'enfant les aires corticales et les circuits cérébraux impliqués dans le traitement phonologique et lexico sémantique d'une tâche de lecture.

Matériel et methods. - Un réseau d'aires cérébrales interconnectées est examiné sur la base d'un modèle structural incluant les cortex supramarginal (aire 40 de Brodmann), fusiforme (aire 37de Brodmann) et frontal inférieur (aires 44/45 de Brodmann) de l'hémisphère gauche. La méthode de modélisation proposée permet d'évaluer une différence de connectivité effective des circuits engagés au cours d'une tâche de lecture de pseudomots entre des enfants dyslexiques et des enfants normaux lecteurs appariés en âge chronologique et lexical.

Résultats. - Chez les patients dyslexiques, contrairement aux groupes témoins appariés par l'âge ou le niveau de lecture, aucune interaction causale n'a été démontrée entre les aires 40 et 44/45 de Brodmann qui constituent les nœuds du circuit d'assemblage phonologique. En revanche, une interaction significative a été retrouvée au niveau du circuit d'adressage lexico sémantique, entre les aires 37 et 44/45 de Brodmann, chez les enfants dyslexiques et les enfants appariés par le niveau de lecture.

Conclusions. - Ces résultats confirment l'existence d'un déficit des processus phonologiques dans la dyslexie développementale.

\section{Introduction}

A number of functional neuroimaging studies have recently tried to identify the brain areas involved in reading [1]. Despite considerable variability between the various studies in terms of functional imaging techniques, methods (subjects or tasks required), or interpretation of data, specific brain areas specialized for the reading process have been identified [2,3]. A framework based on dual route models for reading, derived from neuropsychological observations and experimental psychology, has often been used to interpret clinical and anatomical evidence and functional neuroimaging results [4]. In these models, various specific cognitive processes were identified, such as a rule system for phonological or sublexical relations (grapheme-phoneme conversion), a visual word form area for semantic or lexical access and a phonological output lexicon. Regardless of the adopted theoretical models, these identified cognitive processes are unanimously recognized as being involved in reading [5].

Activation results from the hemodynamic response of regional cerebral blood flow have confirmed multicomponent aspects of processing involved in reading in a large left frontoparietotemporal network. The left inferior prefrontal areas (BA 44/45; BA: Brodmann area) are involved in phonological sublexical processes and in lexical semantic processes [6,7]. Moreover, two pathways have been distinguished: a dorsal pathway including temporoparietal areas and a ventral pathway including occipitotemporobasal areas [8]. The dorsal temporoparietal pathway, composed of the posterior part of the left superior temporal gyrus and the inferior parietal gyrus (supramarginal gyri, BA 40) seems to be involved in receptive language processes, assembled phonology operations and graphophonemical rebuilding $[9,10]$. This pathway may support a grapheme-phoneme conversion system. The ventral inferior occipitotemporobasal pathway includes a junction of anterior lingual and fusiform gyri (BA 37) and is involved in identification of objects although there is a certain amount of controversy concerning the existence of the specific word form area [11,12]. More generally, this pathway appears to be involved in lexicosemantic access [13-15]. Recent papers demonstrate that the fusiform gyrus (BA 37) of the left hemisphere appears to be devoted to binding visual and verbal representations $[16,17]$. While there is an obvious connection between both pathways and between the ventral pathway and the left inferior prefrontal cortex, the relationships remain unclear in normal readers.

Developmental dyslexia is a specific and persistent disorder of reading acquisition, which is observed in the absence of any direct cause, observed in the absence of sensory deficit, low intelligence, backwardness, psychiatric or neurological disorders, or socioeducational deficiency (DSM-IV-R) [18]. In children, a two-year delay in reading is commonly taken to distinguish dyslexic readers, with specific reading disorders evidenced in slowed, less accurate reading and aprosody. The core problem in dyslexia is the phonological deficit in processing, identifying and manipulating the sound structure of words [19]. There is evidence to suggest a neurobiological basis for developmental dyslexia, but the causes remain unknown [20,21]. Functional neuroimaging studies in dyslexia have shown a limited commitment of the temporoparietal junction and posterior part of the left superior and middle temporal gyri in the left hemisphere. Anomalies of activation of the posterior temporoparietal areas in the left hemisphere seem to be 
associated with phonological disorders in dyslexic children $[22,23]$.

However, interpretations of inefficiency of reading processes related to specific cortical areas are often contentious despite adapted methods and tests in dyslexia [23-25]. Evidence of developmental dyslexia is taskspecific, functional rather than structural and concerning cortical circuitry. In 1998 [26], Horwitz et al. developed a new method to examine functional connectivity of the left supramarginal/angular gyrus between occipital and temporal lobe regions during single-word reading tasks by using covariance analyses. They highlighted a functional disconnection of the supramarginal/angular gyrus in men suffering from developmental dyslexia $[27,28]$. Since this work, several studies based on methods of effective connectivity have demonstrated that the nature of the behavioural task dynamically shifts the locus of convergence to the network component specialized for that task [27]. To our knowledge, few studies have investigated the phonological capacities of dyslexic children. The present study was designed to examine effective connectivity within a temporoparietofrontal network comparing dyslexic children and normal readers (matched for chronological age and reading level). For this purpose, we used single-word and pseudoword reading tasks to elucidate more clearly phonological decoding processes. We assume that dyslexic children present a modification of effective connectivity involving the areas responsible for phonological processing and related to the major areas involved in reading [29].

\section{Materials and methods}

\section{Participants}

Eighteen French-speaking children participated in this experiment: six dyslexic children (three girls and three boys; mean age: 10.9 years; range: $10.1-11.4$ ), six chronological age-matched (CA) normally developing children, (three girls and three boys; mean age: 11.1 years, range: $9.7-12.7$ ) and six reading level-matched $(\mathrm{RL})$ normally developing children, (four girls and two boys; mean age: 8.5 years; range: 7.8-9.7), assessed by the Alouette reading test [30]. The mean reading level was 7.2 years in the dyslexic group and 8.0 years and 11.9 years in the control groups (RL and CA, respectively).

Participants were included in the study after a clinical interview and medical questionnaire and psychological testing. All participants were right-handed, had normal nonverbal intelligence (evaluated by the PM47 of Raven, 1947) [31], were not claustrophobic and did not present any visual, attentional, psychiatric or neurological disorders requiring drug treatment, or a metal prosthesis. In addition to assessment of their reading level, a linguistic assessment was conducted to probe for phonological and/or spelling difficulties. These reading and dictation tasks showed that all dyslexic subjects in our study presented phonological disorders, with major difficulties when reading and spelling irregular words. These assessments, although relevant for evaluation of the subject's deficits, did not allow subtyping of the dyslexic children of our study. However, these assessments indicate that the dyslexic children constitute a homogenous group of children suffering from phonological dyslexia.

Informed consent was obtained from participants and their parents after explanation of the aims and procedure of the study. The protocol was approved by the Teaching Hospital Ethics Committee.

\section{Material and tasks}

Participants were asked to perform a task including three conditions during the fMRI investigations: picture-naming, single-word and pseudoword reading. For the picturenaming condition, 260 drawings of common objects were selected from Snodgrass and Vanderwart's set of pictures [32]. For the single-word reading condition, 320 frequent, concrete and regular words (three to seven letters long) were taken from the French Novlex database [33] and 320 pronounceable pseudowords (three to seven letters long) complying with French phonology rules were developed.

The children were asked to either read the words and pseudowords silently or to name the pictures silently as quickly as possible. They had to press a response button with their right index finger as soon as they had read or named the item in order to display the following stimulus. The stimuli were presented to the participant via a mirror system. The stimuli were presented in the centre of the screen and remained visible for a time equal to or greater than the participant's reading time. If the participant had not pressed on the response button after $4 \mathrm{~s}$, the following stimulus was automatically displayed. The participants were informed that their reading and naming times were systematically recorded. They performed a practice block in order to understand the procedure before the experimental task. After the fMRI investigations, children were asked to read and name a list of stimuli used during the scanning to assure that they have correctly performed the experimental fMRI tasks.

\section{Scanning procedure}

Children were scanned through four alternating blocks of words, pseudowords and picture conditions over a total of 12 periods. Each experimental period lasted $40 \mathrm{~s}$, resulting in a total experimental duration of $8 \mathrm{~min}$. The order of conditions was counterbalanced to prevent a possible order effect. The children were randomly assigned to one of the six possible orders.

\section{Path model construction}

Only pseudoword and word conditions were used for the rest of the study, as our exploratory analysis showed that these two conditions revealed a network of diverse activities involved in phonological processing (see appendix, Tables 5 and 6). The path model used in this study is based on a neural network restricted to three topologically distinct brain regions (Fig. 1): supramarginal cortex (BA 40), fusiform cortex (BA 37) and inferior frontal cortex (BA 44/45). 


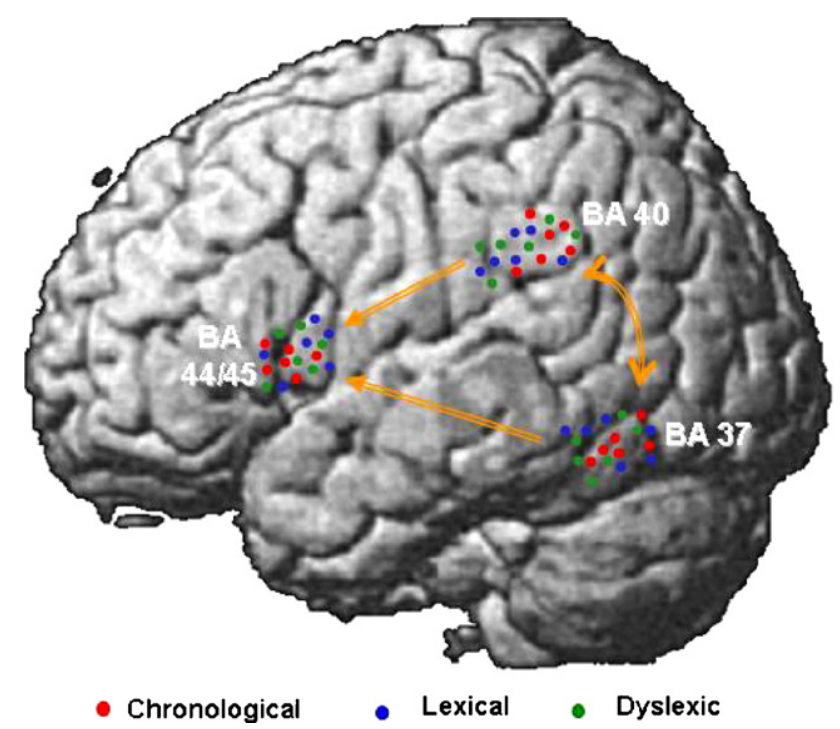

Figure 1 Sagittal projection map showing 54 regions of interest and path diagram of pseudoword reading. Each region of interest is colour-coded according to its group: chronological (red), lexical (blue) and dyslexic (green). Times-series of activated voxels were extracted from these three topologically distinct brain regions: BA 37, BA 40 and BA 44/45.

These cortical regions were selected because they have known reciprocal connections and their involvement in different aspects of reading processing is well documented in recent published functional imaging studies $[8,34,35]$.

\section{Structural equation modeling (SEM)}

We used SEM to construct a pathway model that could account for fMRI data in all regions of interest (ROIs) for the pseudoword condition (Fig. 1). Adjusted signals in the three regions of the left hemisphere extracted from the data set were entered as variables. The structural model was assessed by minimizing the difference between observed and predicted covariances of the fMRI data according to the maximum-likelihood algorithm. In this analysis, the variables are considered in terms of the covariance structure. Analyses were performed using AMOS software (version 5.0.1, Copyright 1994-2003 SmallWaters Corp.) $[36,37]$.

Typically, in SEM, comparison between groups consists of a comparison of models. Stacked matrices, in which the elements are composed of variances and covariances, are considered for each group (see Appendix, Table 7). In this approach, constraints, usually equality constraints are introduced on the estimations of the parameters. For example, the estimate of the values of a path coefficient can be constrained to be equal in the various groups. The group comparison therefore amounts to a comparison between a constrained (fixed parameters) and a non-constrained (free parameters) model. In a non-constrained model, there is one value for each path coefficient and each group. In the constrained model used for group comparison, there is only one value for each parameter common to all groups. The model-comparison process is as follows. First, the algo- rithm estimates the specific parameter values for each group. The fit of the non-constrained model is examined to ensure that the hypothesized causality network can account for the data. The parameters in the constrained model are forced to equality for each two groups. If the groups differ in terms of path connectivity, then the non-constrained model is assumed to provide a better fit than the constrained model. In other words, if the fit of the constrained model (using common values for the parameters) is not significantly different from the fit of the unconstrained model (using specific/different values for the parameters in each group), this test allows us to conclude that the differences between groups must be taken into consideration to model the covariance matrix.

Since the constrained model is nested in the nonconstrained model, the $\chi^{2}$ of the difference between the $\chi^{2}$ of the two models can be used to test the significance of the difference. If this test is statistically significant, then we can conclude that there is a difference between the parameters (i.e. the causal pathways) between the two groups. In order to account for the overall difference found, if any, each pair of parameters can be compared (pair-wise comparison). The test used, which follows a $Z$ distribution, is based on the differences between the parameter values divided by the standard error of measurement of these differences [36].

In order to assess the goodness of fit of the model to the data, we used a set of indicators. Each indicator provides different aspects of goodness of fit. This type of approach using several indicators has been largely validated by simulation studies [38]. We used the test based on the minimization function $\chi^{2}$ or test of exact fit. The root mean square error of approximation (RMSEA) or test of close fit is particularly important because it is relatively independent of the sample size and the number of parameters used in the model [39]. We also used the standardised root mean square residual (SRMR) and the goodness of fit index (GFI), [40] that gives an estimation of the part of variance explained by the model. In addition, we used the Tucker and Lewis index, (TLI in [41]) that provides an estimation of the improvement of the data fit provided by the model tested with regard to the independence model.

\section{fMRI data acquisition}

Neuroimaging data were acquired with a 1.5 Tesla wholebody-MRI system equipped with a head volume coil (Signa; General Electric Medical System, Milwaukee, WI). For each participant, a series of echoplanar functional images (EPI) was collected to provide functional images sensitive to Blood Oxygen Level Dependent (BOLD) contrast. Single-shot EPI acquisitions were performed using a typical T2*-weighted gradient-echo sequence. A total of 3600 images were then obtained for each experimental run, using $213.75-\mathrm{mm}$ thick axial slices. One hundred and fifty EPI volumes with no gap were acquired $(T R / T E=3400 / 45 \mathrm{~ms}$, flip angle $=90^{\circ}$, matrix $=64^{2}, \mathrm{FOV}=240^{2} \mathrm{~mm}^{2}$, isotropic voxel volume $=52.7 \mathrm{~mm}^{3}$ ) for each functional imaging session. The paradigm acquisition time was $8 \mathrm{~min} 30 \mathrm{~s}$. At the end of each functional run, a series of T1-weighted 3D anatom- 
ical images was collected to provide detailed anatomic information. Conventional 3D-imaging consisted of SPGR sequence, matrix $=256^{2}$, flip angle: $35^{\circ}, T R / T E=22 / 8 \mathrm{~ms}$, $\mathrm{FOV}=240^{2} \mathrm{~mm}^{2}, 124$ partitions $-1.5 \mathrm{~mm}$ thick.

\section{Image data processing}

Image preprocessing was performed using Statistical Parametric Mapping software (Methodology group, Wellcome Department of Cognitive Neurology, London, UK: http://www.fil.ion.ucl.ac.uk//spm). The SPM analysis served as a data reduction step in order to identify significant voxels based on the meaningful single pseudoword/word contrast according to the subtraction method.

The first four and last two scans were discarded. For each subject and each session, all EPI volumes were corrected to adjust for within-volume time differences and realigned to the last volume to correct for head movements. The functional scans were then spatially normalized into the standard stereotactic space of the Talairach atlas [42]. Spatial smoothing with a $6 \mathrm{~mm}$ FWHM Gaussian kernel was performed. The hemodynamic responses were modelled as a box-car function convolved with a synthetic hemodynamic response function. A single subject, fixedeffects model analysis was performed for each individual subject in order to prepare the extraction of the BOLD time series. In each single subject analysis, a significance level of $p=0.05$ was applied to detect activated voxels for the meaningful single pseudoword/word contrast. Local maxima were located within the predefined brain regions and then assigned to a Brodmann area. Talairach Daemon software and mni2tal tool (http://www.matthijsvink.com/tools.html) were used to automatically define Talairach atlas labels and to convert coordinates from MNI brain for equivalent Talairach coordinates using a nonlinear transformation respectively. We used the mni2tal algorithm to ensure that the activated pixels actually corresponded to the predefined brain regions (http://www.mrccbu.cam.ac.uk/Imaging/Common/mnispace.shtml).

\section{fMRI data extraction for SEM}

BOLD time-series of activated pixels were extracted from BA 40, BA 44/45 and BA 37 regions (with reference to the structural model) using the Marsbar toolbox (http://marsbar.sourceforge.net/). The time-series extraction was performed separately in each area using a $6 \mathrm{~mm}$ radius spherical $\mathrm{ROI}$. We extracted the average signal of the selected ROI using the SPM-scaling design and the meanvalue options.

Individual time-series were therefore centred and reduced across conditions concatenated into a scan * subjects matrix $\left(48^{*} 6\right)$. This normalization procedure is required to allow comparison of BOLD signals across subjects and sessions. Local maxima within predefined cortical functional areas and time-series extracted for the SEM analysis were identified for each subject and each ROI in the left hemisphere.
Table 1 Mean response times (in milliseconds) as a function of task and groups.

\begin{tabular}{llll}
\hline & Naming & Words & Pseudowords \\
\hline CA & 1461.8 & 1003.5 & 1319.8 \\
RA & 1699.5 & 1388 & 1943.5 \\
DYS & 2031.7 & 1872.5 & 2230.5 \\
\hline
\end{tabular}

\section{Results}

\section{Experimental data}

Response times were submitted to analyses of variance (ANOVAs) with groups (dyslexic and controls) as experimental factor. For all analyses, the conventional level of 0.05 for statistical significance was adopted. There was a significant difference in response times among the three groups $(F(2,15)=9.61 ; p=0.002)$.

The dyslexics were slower (2044.89) than the control groups $(C A=1261.72 ; R A=1677)$. Only the difference between dyslexics and reading control group (RA) was not significant. Response times were significantly faster in the word-reading task (1421.33) followed by the picturesnaming task (1731) and finally the pseudoword reading task (1831.28), $F(2,30)=14.74, p<0.0001$. Planned comparisons showed that only the difference between pictures and pseudowords was not significant. This factor did not interact significantly with the groups factor, $F(4,30)=1.49$, ns. The Table 1 shows the mean response times as a function of task and groups.

\section{fMRI data}

The results of univariate comparisons (two-sample $t$-test) of the brain regions activated in the chronological and dyslexic groups and in reading level-matched and dyslexic groups are shown in Table 5 and $B$, respectively in the appendix, for the main regions of interest.

Path diagrams are presented separately in Fig. 2 for the dyslexic/CA normal readers groups $(A)$ and dyslexic/RL groups (B). In each diagram, one correlation and two one-way paths (recursive model, i.e. all arrows are unidirectional without feedback loops) are represented by a double arrow and single arrows, respectively. The two connections chosen for SEM analysis were unidirectional to ensure mathematically robust estimates of connection strengths. A correlational non-causal relationship was also introduced into the pathway model based on the hypothesis of a relationship between the two regions, although a precise hypothesis cannot be proposed concerning the causality between the supramarginal (BA 40) and the fusiform cortex (BA 37).

We first tested the fit between the predicted model and the empirical data for each group using an iterative maximum likelihood algorithm. Only path values obtained from the non-constrained model are shown in Fig. 2. Residual variances were estimated for each group separately and are presented in Table 2. 
Table 2 Residual variances calculated in the inferior frontal cortex (BA 44/45) in dyslexic, chronological age-matched and reading level-matched groups.

\begin{tabular}{llll}
\hline & \multicolumn{2}{l}{ Residual variances } & \\
\cline { 2 - 4 } & Dyslexic group & Chronological age group & Reading level group \\
\hline BA 44/45 & 0.92 & 0.78 & 0.80 \\
\hline
\end{tabular}

\section{Path analysis comparison between dyslexic and chronological age-matched (CA) children}

The predicted structural network for the non-constrained model fits the experimental data $\left[\chi_{(2)}^{2}=0.13, p=0.938\right]$. The values for other indices of fit, RMSEA $=0.000$ and $\mathrm{GFI}=1.000, \mathrm{SRMR}=0.0012, \mathrm{TLI}=1.000$ are higher than the cut-off value usually recommended in the literature, in particular the combinatory rules recommended by [38] to indicate that the model adequately fits the data. In the dyslexic group (Fig. 2), the path coefficient indicates a

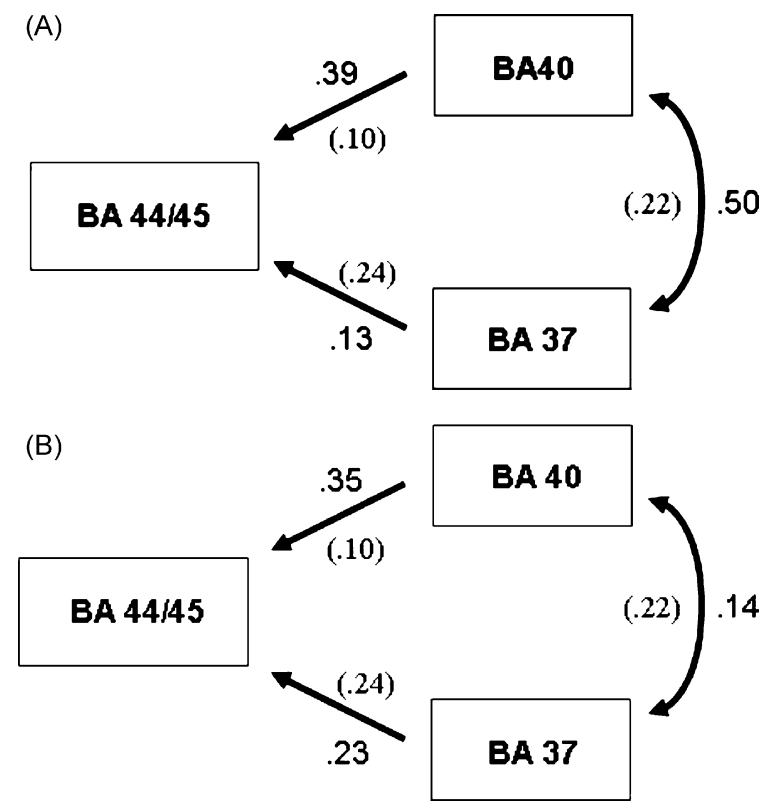

Figure 2 Path diagrams from the causal analysis using structural equation modeling involving left hemisphere. Inferior frontal cortex (BA 44/45), supramarginal cortex (BA 40) and fusiform cortex (BA 37) are shown. The values of the path coefficients in chronological and dyslexic (in parentheses) groups are indicated. "middle" size effect, according to Cohen's conventions on effect sizes [43], from BA 37 to BA 44/45. The non-reciprocal connection between BA 40 and BA 44/45 indicates a "weak" connection that was not statistically significant for the usual limit of $\alpha=0.05$. In the CA group (Fig. 2), a weak unidirectional connection from BA 37 to BA 44/45 was observed. On the other hand, our results show a "strong" positive influence from BA 40 to BA 44/45. As the non-constrained model can be assumed to be correct, the dyslexic and chronological groups can be compared by model comparison. The difference between $\chi^{2}$ of the non-constrained and constrained models $\left[\chi^{2} \operatorname{diff}(2)=11.415, p<0.003\right]$ indicates a global statistically significant difference between the two models and therefore between the dyslexic and CA groups. Critical ratios for the relevant pairs of path coefficient differences are indicated in Table 3.

The results of the pairwise comparisons between the group paths, for the non-constrained model reveal significant differences in the strength $(p<0.001)$ of the connection between BA 40 and BA 44/45 and in the relationship between BA 40 and BA 37. The connection between BA 37 and BA $44 / 45$ tends to be higher in the dyslexic group than in the CA group.

\section{Path analysis comparison between dyslexic and reading level-matched $(\mathrm{RL})$ children}

The pattern of the results for RL children is shown in Fig. $2 \mathrm{~B}$. The goodness of fit for the non-constrained model is in agreement with a good convergence between the predicted model and the empirical data $\left[\chi_{(2)}^{2}=0.131, p=0.936\right]$ and was confirmed by the other indices: RMSEA $=0.000$, $\mathrm{GFI}=1.000, \mathrm{SRMR}=0.0012, \mathrm{TLI}=1.000$. Comparison of the dyslexic and $\mathrm{RL}$ groups revealed a significant difference $\left[\chi^{2} \operatorname{diff}(3)=11.173, p<0.011\right]$. In the RL group (Fig. 2), the connection strength between BA 40 and BA 44/45 indicates a "strong" positive influence of BA 40 on BA 44/45. A "middle" size effect was observed from BA 37 to BA 44/45. Critical ratios for the relevant

Table 3 Estimates of regression weights for the dyslexic and chronological age-matched groups.

\begin{tabular}{|c|c|c|c|c|c|c|}
\hline & \multicolumn{3}{|l|}{ Dyslexic group } & \multicolumn{3}{|c|}{ Chronological age group } \\
\hline & Path coefficients & CR & $p$ & Path coefficients & CR & $p$ \\
\hline BA $37 \rightarrow$ BA $44 / 45$ & 0.237 & 4.030 & $* * *$ & 0.135 & 2.211 & * \\
\hline BA $40 \rightarrow$ BA $44 / 45$ & 0.101 & 1.722 & 0.08 & 0.388 & 6.345 & $* * *$ \\
\hline
\end{tabular}

Nonstandardized path coefficients and critical ratio $(C R)$ for regression weights are presented. Level of significance for regression weights are ${ }^{*} p<0.05,{ }^{* *} p<0.01,{ }^{* * *} p<0.001$. Inferior frontal cortex (BA 44/45), supramarginal cortex (BA 40) and fusiform cortex (BA 37). 
Table 4 Estimates of regression weights for the dyslexic and reading level-matched groups.

\begin{tabular}{|c|c|c|c|c|c|c|}
\hline & \multicolumn{3}{|l|}{ Dyslexic group } & \multicolumn{3}{|c|}{ Reading level group } \\
\hline & Path coefficients & CR & $p$ & Path coefficients & $\mathrm{CR}$ & $p$ \\
\hline BA $37 \rightarrow$ BA $44 / 45$ & 0.237 & 4.030 & $* * *$ & 0.233 & 4.330 & *** \\
\hline BA $40 \rightarrow$ BA $44 / 45$ & 0.101 & 1.722 & 0.08 & 0.352 & 6.537 & $* * *$ \\
\hline
\end{tabular}

Nonstandardized path coefficients and critical ratio $(C R)$ for regression weights are presented. Level of significance for regression weights are " $p<0.05,{ }^{* *} p<0.01,{ }^{* * *} p<0.001$. Inferior frontal cortex (BA 44/45), supramarginal cortex (BA 40) and fusiform cortex (BA 37).

pairs of path coefficient differences are indicated in Table 4.

The results of the pairwise comparisons between the group paths reveal a significant difference in strength $(p<0.01)$ for the connection between BA 40 and BA44/45 and a nonsignificant difference of strength between BA 40 and BA 37. The connection between BA 37 and BA 44/45 tends to be equal in the two groups.

\section{Discussion}

\section{Experimental data}

Dyslexic children presented the same pattern of response times as normal readers: they took less time to read words than to identify pseudowords or images. In contrast, they were slower than chronological age-matched normal readers, regardless of the stimulus. Dyslexic children processed fewer items than normal readers. This result is coherent with the experimental data previously collected by several researchers. However, the number of items processed do not seem to be sufficient to account for differences in cerebral activation. The group of reading level-matched children processed almost as many words as older children, but differences were nevertheless observed in cerebral activation between these two groups. Conversely, similarities were observed in terms of activation between aged-matched normal readers and dyslexics children, despite the observed differences between these two groups in terms of number of items processed. Cerebral activation differences observed between groups therefore cannot be explained by differences of processing time according to the type of stimulus. Furthermore, time of each item $(4 \mathrm{~s})$ was chosen to be sufficiently long to allow dyslexic children process a maximum of items. Response times appear to be a more relevant cognitive variable than the number of items processed, as they indicate that the child performed the reading. Because, firstly the means of response times recorded for any children are lower than the $4 \mathrm{~s}$ limit time and secondly the time results of dyslexics are not different than these of aged-matched normal readers. We can suppose that the experimental fMRI task was correctly performed such as observed in cognitive investigations. This methodological choice seems to be correctly adapted to the objectives of this study and to our specific population and allowed us to interpret activation as differences of connectivity pattern and not as differences of dyslexic's performances.

\section{Differences in functional connectivity}

The results of the present study suggest differences in connectivity commitment and strength within a temporoparietofrontal cortical network studied in groups of dyslexic children and normal readers on pseudoword reading tests. The two dorsal and ventral reading pathways, mediated by temporoparietal (BA 40) and occipitotemporobasal (BA 37) pathways, respectively, presented different relations between the groups of children.

\section{Dorsal temporoparietal pathway}

In the two groups of normal-reader children (RL and CA), pathway coefficients presented a significant strength for their effective connectivity from BA 40 to BA 44/45 with a strong positive influence, in contrast to the group of dyslexic children. Results in reading level-matched group $(\mathrm{RL})$, beginner in reading learning, as well as in chronological age-matched group (CA), confirmed normal reader children, showed significant effective connectivity of this pathway, implicating the dorsal supramarginal cortex (BA 40 ) in phonological processes. In dyslexic children, the dorsal temporoparietal pathway does not appear to participate in the reading capacities of pseudowords. As this pathway is known to be involved in phonological reading processes, the results can be interpreted to be a consequence of the phonological deficits of the developmental dyslexic children participating in this study.

\section{Ventrobasal pathway}

Different results were obtained for the ventral basal fusiform cortex (BA 37) pathway involved in lexicosemantic processing, as dyslexic children, as well as RL young children showed a middle size effect in connectivity from BA 37 to BA 44/45, higher than in CA children. This reading pathway appears to be more extensively used in dyslexic children and the path coefficient appears to decrease with increasing reading level and experience.

\section{Reading development and dyslexia}

The results for correlations between the supramarginal cortex (BA 40) and the fusiform cortex (BA 37) for dyslexic children were significantly different from those for $C A$ normal reader children, but not for $\mathrm{RL}$ children. This difference can be explained by developmental strengthening of 
the readers' decoding capacities: morphological (lexicosemantic processing) and phonological (graphophonological conversion) processes appear to function together on pseudoword reading tasks, by the use of reciprocal comparisons of processing and their outputs. The weaker relationship between BA 40 and BA 37 in RL and dyslexic children compared to CA children suggests that this reciprocal processing between the two reading pathways is immature or dysfunctional [27]. This hypothesis is consistent with the findings reported by Vigneau et al. [17] that morphological processing can also be involved in processing prelexical units in pseudoword reading in adult normal readers. These results also agree with the hypothesis of a third reading pathway using analog processing between lexicosemantic and phonologic processing [44].

The observation of partially enhanced connectivity strength is in line with previous reports on functional disconnection of temporoparietal areas in developmental dyslexia $[28,45,46]$. Phonological decoding problems are the most ubiquitous signs of developmental dyslexia [22]. Thus, in dyslexic children, activation of the inferior frontal cortex (BA 44/45), which is thought to represent ongoing articulation processes in reading, would be essentially due to lexicosemantic processing via functional connectivity with the basal fusiform cortex (BA 37). Neuroanatomical structural differences have been identified between control and dyslexic subjects and the present study clearly demonstrates that these differences are related to behavioral functional deficits, more specifically those observed in phonological coding.

Reading is a complex task involving multiple cognitive processes related to different cerebral areas and, to our knowledge, no fMRI study of effective connectivity in reading tasks has been previously conducted to demonstrate a relationship between functional reading cognitive processes and a neurovascular network [27]. The present findings provide evidence for the existence of a phonological deficit in developmental dyslexia. Despite the fact that these results were obtained in a small number of children, this study shows that dyslexic children fail to use a brain path normally specialized in phonological processing, but rather use a brain path involved in lexicosemantic processing. It would also be interesting to analyze effective connectivity within a network including a larger number of brain regions, as the three regions tested in our model do not appear to be the only ones involved in word or pseudoword reading tasks. Consequently, it would be interesting to include other regions in the network, particularly regions in the right hemisphere $[29,47]$.

Another important aspect of this study concerns the clinical implications of effective connectivity. Firstly, this method could be used to show different reading strategies used by dyslexic children, as the various forms of dyslexia identified by certain authors in the literature can be assumed to be associated with different strengths and areas of connectivity [48]. For example, dyslexic children who show a defect of visual word form processing (surface dyslexia) should present a "stronger" connection between BA 40 and BA 44/45 compared to phonological dyslexic children. Secondly, our method is useful to test the effects of remediation. We can suppose that differences observed in effective connectivity in dyslexic children should tend to disappear after training sessions, as several studies have shown that activation was increased in specific parts of the brain involved in phonological or morphological processing $[24,49,50]$.

Finally, it could be argued that our SEM analysis is limited to a restricted network and that a different (presumably more extensive) network should have been investigated, given that many brain regions were actually activated in the reading tasks as indicated by univariate analysis (data not shown). A very large number of possible interconnections could obviously be investigated. However, plausible combinations are generally explored within the so-called "automated search" procedure in SEM approach [51]. Another interesting use of SEM would have been to generate alternative models in order to identify the most plausible models. This latter approach is generally referred to as "specification search" [52,53]. These two uses of SEM are distinct from the confirmatory approach that was chosen here. Both automated and specification search programs were far beyond the scope of the present study.

\section{Limitations}

The rigorous selection of subjects results in a small samples of subjects. However, the significance of our statistical results on these small samples allows us to expect, due to the low level of variance, more powerful effects on larger samples. We prefered to favour the homogeneity and representativeness of our group to the detriment of the sample size.

In this study, imaging and analytical comparisons of the activations of BA $37, \mathrm{BA} 40$ and BA $44 / 45$ were both very

Table 5 Results show that the activations in the brain regions which were a priori included in our structural equation model construction are statistically different between the two groups.

\begin{tabular}{|c|c|c|c|c|c|}
\hline \multirow[t]{2}{*}{ Regions } & \multirow[t]{2}{*}{ BA } & \multicolumn{3}{|c|}{ Stereotaxic coordinates } & \multirow[t]{2}{*}{$t$} \\
\hline & & $x$ & $y$ & $z$ & \\
\hline Temporal cortex & 37 & -47 & -49 & 3 & 2.31 \\
\hline Inferior parietal cortex & 40 & -52 & -44 & 36 & 3.46 \\
\hline Inferior/pars opercularis frontal cortex & 44 & -45 & 10 & 24 & 4.80 \\
\hline Inferior/pars triangularis frontal cortex & 45 & -42 & 35 & 4 & 5.85 \\
\hline
\end{tabular}

BA: Brodmann areas; $x, y, z$ : Talairach and Tournoux coordinates, $t$ values, (unilateral comparison lexical group > dyslexic group), $p=0.05$, degree of freedom $=10$. A two-sample $t$-test comparison between regions activated in lexical and dyslexic groups is presented. 
Table 6 Results show that the activations in the brain regions which were a priori included in our structural equation model construction are statistically different between the two groups.

\begin{tabular}{|c|c|c|c|c|c|}
\hline \multirow[t]{2}{*}{ Regions } & \multirow[t]{2}{*}{ BA } & \multicolumn{3}{|c|}{ Stereotaxic coordinates } & \multirow[t]{2}{*}{$t$} \\
\hline & & $x$ & $y$ & z & \\
\hline Temporal cortex & 37 & -47 & -52 & 3 & 2.31 \\
\hline Inferior parietal cortex & 40 & -42 & -39 & 35 & 3.30 \\
\hline Inferior/pars opercularis frontal cortex & 44 & -47 & 19 & 34 & 2.90 \\
\hline Inferior/pars triangularis frontal cortex & 45 & -53 & 24 & 24 & 3.43 \\
\hline
\end{tabular}

BA: Brodmann areas; $x, y, z$ : Talairach and Tournoux coordinates, $t$ values, (unilateral comparison chronological group $>$ dyslexic group), $p=0.05$, degree of freedom $=10$. A two-sample $t$-test comparison between regions activated in lexical and dyslexic groups is presented.

Table 7 This table represents the matrix of variances and covariances of each group calculated in the three distinct brain regions: BA 40, BA 37 and BA 44/45.

\begin{tabular}{llll}
\hline Groups & BA 40 & BA 37 & BA 37 \\
\hline Chr & 0.499 & - & - \\
Lex & 0.138 & - & 0.327 \\
Dys & 0.221 & 0.278 & BA 44/45 \\
Chr & 0.449 & 0.255 & \\
Lex & 0.378 & 0.152 & \\
Dys & 0.152 & \\
\hline
\end{tabular}

Chr: chronological; Lex: lexical; Dys: dyslexic groups.

challenging issues for a number of reasons. First, the temporal cortex and inferior frontal cortex have been described as a region that is highly susceptible to EPI artefact. Second, it is not always easy to exactly define the same areas in each subject because of:

- anatomical differences between individuals;

- differences in brain maturation (plasticity) in the frontal areas in children;

- vascular differences (geometry and large vessels) to which contrast BOLD is sensitive, preventing precise localization of the functional areas.

In addition, it can be argued that our SEM analysis is limited to a restricted network and that a different (presumably more extensive) network should have been investigated, given that many brain regions were actually activated in the reading tasks as indicated by univariate analysis (data not shown). A very large number of possible interconnections could obviously be investigated. However, plausible combinations are generally explored within the so-called "automated search" procedure in SEM approach [51]. Another interesting use of SEM would have been to generate alternative models in order to identify the most plausible models. This latter approach is generally referred to as "specification search" [52,53]. These two uses of SEM are distinct from the confirmatory approach that was chosen here. Both automated and specification search programs were far beyond the scope of the present study.

\section{Acknowledgements}

This work was partially supported by a FEDER Program Grant "pôle régional de recherche et développement technologique : génie biomédical périnatalité - enfance"'.

\section{Appendix A}

Tables 5-7.

\section{References}

[1] Price CJ. The anatomy of language: contributions from functional neuroimaging. J Anat 2000;197(Pt 3):335-59.

[2] Demonet JF, Taylor MJ, Chaix Y. Developmental dyslexia. Lancet 2004;363(9419):1451-60.

[3] Jobard G, Crivello F, Tzourio-Mazoyer N. Evaluation of the dual route theory of reading: a metanalysis of 35 neuroimaging studies. Neuroimage 2003;20(2):693-712.

[4] Coltheart M, Rastle K. Serial processing in reading aloud: evidence for dual route models of reading. J Exp Psychol 1994;6:1197-211.

[5] Price CJ, Moore CJ, Humphreys GW, Wise RJ. Segregating semantic from phonological processes during reading. J Cogn Neurosci 1997;9:727-33.

[6] Fiez JA. Phonology, semantics, and the role of the left inferior prefrontal cortex. Hum Brain Mapp 1997;5(2):79-83.

[7] McDermott KB, Petersen SE, Watson JM, Ojemann JG. A procedure for identifying regions preferentially activated by attention to semantic and phonological relations using functional magnetic resonance imaging. Neuropsychologia 2003;41(3):293-303. 
[8] Price CJ, Mechelli A. Reading and reading disturbance. Curr Opin Neurobiol 2005;15(2):231-8.

[9] Joubert $S$, Beauregard $M$, Walter $N$, et al. Neural correlates of lexical and sublexical processes in reading. Brain Lang 2004;89(1):9-20.

[10] Simos PG, Breier JI, Wheless JW, et al. Brain mechanisms for reading: the role of the superior temporal gyrus in word and pseudoword naming. Neuroreport 2000;11(11):2443-7.

[11] Cohen L, Dehaene S. Specialization within the ventral stream: the case for the visual word form area. Neuroimage 2004;22(1):466-76.

[12] Price CJ, Devlin JT. The myth of the visual word form area. Neuroimage 2003;19(3):473-81.

[13] Herbster AN, Mintun MA, Nebes RD, Becker JT. Regional cerebral blood flow during word and nonword reading. Hum Brain Mapp 1997;5(2):84-92.

[14] Shaywitz BA, Pugh RP, Constable RT, et al. Localization of semantic processing using functional magnetic resonance imaging. Hum Brain Mapp 1995;2:149-58.

[15] Vandenberghe R, Price C, Wise R, Josephs O, Frackowiak RS. Functional anatomy of a common semantic system for words and pictures. Nature 1996;383(6597):254-6.

[16] Pernet C, Celsis P, Demonet JF. Selective response to letter categorization within the left fusiform gyrus. Neuroimage 2005;28(3):738-44.

[17] Vigneau M, Jobard G, Mazoyer B, Tzourio-Mazoyer N. Word and non-word reading: what role for the Visual Word Form Area? Neuroimage 2005;27(3):694-705.

[18] DSMIVTR. Diagnostic and Statistical manual of Mental Disorders. Washington, DC: American Psychiatric Association; 2000. Fourth Edition, Text Revision.

[19] Ruff S, Marie N, Celsis P, Cardebat D, Demonet JF. Neural substrates of impaired categorical perception of phonemes in adult dyslexics: an fMRI study. Brain Cogn 2003;53(2):331-4.

[20] Habib M. The neurological basis of developmental dyslexia: an overview and working hypothesis. Brain 2000;123(Pt 12):2373-99.

[21] Ramus F. Neurobiology of dyslexia: a reinterpretation of the data. Trends Neurosci 2004;27(12):720-6.

[22] Georgiewa P, Rzanny R, Hopf JM, et al. fMRI during word processing in dyslexic and normal reading children. Neuroreport 1999;10(16):3459-65.

[23] Temple E, Poldrack RA, Salidis J, et al. Disrupted neural responses to phonological and orthographic processing in dyslexic children: an fMRI study. Neuroreport 2001;12(2):299-307.

[24] Small SL, Flores DK, Noll DC. Different neural circuits subserve reading before and after therapy for acquired dyslexia. Brain Lang 1998;62(2):298-308.

[25] Zabell C, Everatt J. Surface and phonological subtypes of adult developmental dyslexia. Dyslexia 2002;8(3):160-77.

[26] Horwitz B, Rumsey JM, Donohue BC. Functional connectivity of the angular gyrus in normal reading and dyslexia. Proc Natl Acad Sci U S A 1998;95(15):8939-44.

[27] Hampson M, Tokoglu F, Sun Z, et al. Connectivity-behavior analysis reveals that functional connectivity between left BA39 and Broca's area varies with reading ability. Neuroimage 2006;31(2):513-9.

[28] Milne D, Syngeniotis A, Jackson G, Corballis M. Mixed lateralization of phonological assembly in developmental dyslexia. Neurocase 2002;8:205-9.

[29] Stanberry LI, Richards T, Berninger VW, et al. Spectral differences in language processing areas in good and dyslexic readers. Seattle, Washington, USA: ISMRM 14th Scientific Meeting \& Exhibition; 2006.
[30] Lefavrais P. Test de l'Alouette. Paris: Éditions du Centre de Psychologie Appliquée; 1967.

[31] Raven JC. Progressives Matrices, séries A, B, C, D, E (PM-38). Paris: Éditions Scientifiques et Psychotechniques; 1980.

[32] Snodgrass JG, Vanderwart M. A standardized set of 260 pictures: norms for name agreement, image agreement, familiarity, and visual complexity. J Exp Psychol Learn Mem Cogn 1980;6(2):174-215.

[33] Lambert E, Chesnet D. NOVLEX, base de données lexicales pour les élèves de primaire. Annee Psychol 2002;101:277-88.

[34] Catani M, Jones DK, ffytche DH. Perisylvian language networks of the human brain. Ann Neurol 2005;57(1):8-16.

[35] Vitali P, Abutalebi J, Tettamanti M, et al. Generating animal and tool names: an fMRI study of effective connectivity. Brain Lang 2005;93(1):32-45.

[36] Arbuckle JL. Amos 5. 0 update to the Amos user's guide. Chicago: SmallWaters Corporation; 2003.

[37] Arbuckle JL, Wothke W. Amos 4.0 user's guide. Chicago: SmallWaters Corporation; 1999.

[38] Hu L, Bentler PM. Cutoff Criteria for Fit Indexes in Covariance Structure Analysis: conventional Criteria Versus New Alternatives. Struct Equat Model 1999;6:1-55.

[39] Browne HW, Cudeck R. Alternative ways of assessing model fit. In: Bollen KA, Long JS, editors. Testing Structural Equations Models. Newbury Park, CA: Sage Publications; 1993.

[40] Jöreskog KG, Sörbom D. LISREL 8.5 user's reference guide. Chicago, Ill: Scientific Software International; 2000.

[41] Bentler PM, Bonett DG. Significance tests and goodness of fit in the analysis of covariance structure. Psychol Bull 1980;88:588-606.

[42] Talairach J, Tournoux P. Co-Planar Stereotaxic Atlas of the Human Brain: 3-Dimensional Proportional System: An Approach to Cerebral Imaging. New-York: Medical Publisher; 1998.

[43] Cohen J. A power primer. Psychol Bull 1992;112(155-159).

[44] Erskine JM, Seymour PHK. Proximal analysis of developmental dyslexia in adulthood: The cognitive mosaic model. J Educ Psychol 2005;97:406-24.

[45] Rumsey JM, Andreasson P, Zametkin AJ. Failure to activate the left temporo-parietal cortex in dyslexia. An Oxygen-15 Emission Tomographic Study. Arch Neurol 1997;49:527-34.

[46] Shaywitz BA, Shaywitz SE, Pugh KR, et al. Disruption of posterior brain systems for reading in children with developmental dyslexia. Biol Psychiatr 2002;52(2):101-10.

[47] Richards TL, Aylward EH, Berninger VW, et al. Individual fMRI activation in orthographic mapping and morpheme mapping after orthographic or morphological spelling treatment in child dyslexics. J Neurolinguist 2006;19:56-86.

[48] Castles A, Coltheart M. Varieties of developmental dyslexia. Cognition 1997;47:149-80.

[49] Aylward EH, Richards TL, Berninger VW, et al. Instructional treatment associated with changes in brain activation in children with dyslexia. Neurology 2003;61(2):212-9.

[50] Temple E, Deutsch GK, Poldrack RA, et al. Neural deficits in children with dyslexia ameliorated by behavioral remediation: evidence from functional MRI. Proc Natl Acad Sci U S A 2003;100(5):2860-5.

[51] Bullmore E, Horwitz B, Honey G, Brammer M, Williams S, Sharma T. How good is good enough in path analysis of fMRI data? Neuroimage 2000;11(4):289-301.

[52] MacCallum R. Specification searches in covariance structure modeling. Psychol Bull 1986;100:107-20.

[53] MacCallum RC, Wegener DT, Uchino BN, Fabrigar LR. The problem of equivalent models in applications of covariance structure analysis. Psychol Bull 1993;114:185-99. 